Check for updates

1 Dutch Health and Youth Care Inspectorate, the Netherlands

2 Erasmus School of Health Policy \& Management in Rotterdam

Cite this as: BMJ 2021;375:n2695 http://dx.doi.org/10.1136/bmj.n2695 Published: 04 November 2021

\section{Turning patient engagement into the "new normal"}

\section{These authors reflect on how covid-19 has impacted on patient participation in policy and decision making in the Netherlands}

Sorien Kleefstra, , , lan Leistikow,

The value of patient participation in policy and decision making is broadly endorsed in the Netherlands, however, the covid-19 pandemic has shown that in times of crisis we do not practice what we preach. Unfortunately, this mirrors experiences in other parts of the world where the exclusion of patient input has caused multiple missed opportunities to mitigate the predictable impact of wide scale service reconfiguration. ${ }^{1}$ These experiences highlight the importance of "nothing about us without us," especially in times of crisis.

At the onset of the covid-19 pandemic in March 2020, the Dutch Health and Youth Care Inspectorate regularly spoke with 25 Dutch patient and client organisations (PCO's). The PCO's varied from large, national categorical PCO's for specific patient groups (for instance for people with mental health issues, oncology patients, or informal care givers), to general PCO's for all care sectors and all patients on a national, regional, or local level. The inspectorate was eager to understand patients' and carers' perspectives on the quality of care they received during the covid-19-pandemic. One of the urgent messages that PCO's told us was that patient rights and participation were restricted from the very first moment that the crisis erupted. On every level patient participation was limited: from individual care plans, to the engagement of patient councils in care organisations, to input in national policy.

\section{National level}

Before the pandemic, large PCO's had regular meetings with their "own" policy department within the Ministry of Health and Welfare, together with health insurance companies and providers. During the pandemic they used these meetings to share information about the quality of care and to offer advice. Although they were satisfied that they were being listened to in these meetings, PCO's had no influence on the outbreak management team that managed the crisis at a national level, and therefore they had no input into crisis policy and decision making.

In the first phase of the pandemic, the full attention of the outbreak management team was on acute hospital care. As a consequence, the biomedical perspective dominated the policy decisions. The concerns raised by PCO's regarding consequences for long term care and youth care, or the importance of recognising regional or local differences, were not taken into account by the outbreak management team. This led to multiple missed opportunities to improve policy decisions, for example: reducing the distressing consequences of the ban on visitors in long term care wards and the huge impact of these policy decisions on informal care givers; addressing the limited availability and distribution of personal protective equipments for informal care givers or care home and long term care professionals;

understanding that the government's communication about covid-19 was too complex to understand and too general for specific patient groups; realising that the information given to the public about scaling down regular care was insufficient.

When, by the end of May 2020, the worst of the first phase of the covid pandemic had passed, PCO's were again not consulted on decisions regarding the return to regular care, eliminating backlogs, or re-organising care to fit in the national pandemic preventive measures ("the new normal"). An example of a missed opportunity this caused regards the widespread implementation of tele-consultations. In many healthcare sectors digital tele-consultations were seen as a good alternative for "live" meetings with care providers. However, many patients with mental health concerns did not experience this as an adequate alternative. Although the PCO for patients with mental health issues addressed this issue regularly, the policy decision makers neglected it.

\section{Regional level}

In the Netherlands, there are nine regional PCO's representing patients from all healthcare sectors and social care. These are committed to improving regional care in the interest of, and together with, patients. These PCO's have regular meetings with regional care providers and municipalities. However, they are not a formal partner in any of the regional care networks. Individual patients with questions or complaints can turn to these PCO's for support. The funding for regional PCO's varies by region and was reduced in recent years, despite their public function, and a lot of tasks have to be done by volunteers.

From the beginning of the pandemic the regional PCO's tried to get a seat at the regional policy and decision making table. However, most of them did not succeed and were therefore not informed about regional decisions until afterwards. These decisions concerned the organisation of acute regional care, or the improvement of the collaboration between local care providers. For most PCO's, having a seat at the regional decision table improved during the pandemic, however, often they were present as an agenda member only, without voting rights. They were never sure if their input was taken into account by those who ultimately made the decisions and had to fight for their place at the table over and over again. When the second wave started in September 
2020, the regional crisis teams again excluded most of the regional PCO's and focused on acute care instead of the health and social care in the region as a whole, as advocated by the regional PCO's. By December 2020, some of the PCOs were structurally involved, while others gave up the fight and now focus on supporting and providing information for their members.

\section{Organisational level}

At a provider level, patient and family councils were immediately sidelined when the covid pandemic hit, despite an existing Dutch law on patient participation in care organisations. In the Netherlands patient and family councils have a legal position within long term care organisations and hospitals. They have a voice in organisational policy making. However, during the pandemic, policy decisions and measures were often made without consulting, let alone engaging, patient and family councils as there were concerns that this would delay acute decision making.

On 1 July 2020, a new version of the Dutch law on patient participation (WMCZ 2018) came into effect. This law replaced the right for patient councils to advise with the requirement that patient councils agree on policy decisions regarding quality, safety, hygiene, and all other arrangements applicable to clients. However, the covid crisis hindered the implementation of the new law. Firstly because implementing a new law was not the first priority of healthcare organisations which were struggling to cope with the crisis. But also because the Dutch Health and Youth Care Inspectorate decided not to uphold the law straight away to give organisations more time for implementation. PCO's noticed that as a consequence patient and family councils were still not involved in organisational policy and decision making processes. They warned the inspectorate that some organisations subsequently took the opportunity to deliberately delay implementing the law.

So what can we learn?

During the pandemic there was a steep decrease of reports by family and informal care givers due to visiting restrictions, and live inspections were reduced to almost none, so both the formal and informal supervision on quality of care were impaired. Inspectors quickly became used to phoning healthcare providers to stay informed, and experienced how they could, in some sectors, engage with every single provider within just two or three weeks. This normalised phone contacts which, pre-covid, would have been planned visits or meetings. At the same time, the Inspectorate realised it also needed to engage with the patients' perspective more. This prompted the policy of regularly phoning with PCO's and proved to be an efficient, easy, and cheap way of collecting information on the patient and public perspective. But it also showed that the concerns of PCO's were not heard by policy makers.

The most important lesson is this: policy makers' exclusion of the patient perspective led to many missed opportunities for preventing severe unintended consequences of local, regional, and national policy on the wellbeing of the most vulnerable members of our society. But it would be too easy to shift the blame for this on the policy makers alone. In the Netherlands not even a law could ensure patients were sufficiently included in their healthcare. This shows that what we preach is not yet embedded in our DNA, and that good intentions do not guarantee something will be done well when push comes to shove. We must use the lessons of this "setback" to take two steps forward and turn patient engagement, especially during a crisis, into the "new normal."
Richards T, Scowcroft HBM)'s international patient and public advisory panel. Patient and public involvement in covid-19 policy making. BMJ 2020;370:m2575. doi: 10.1136/bmj.m2575. pmid: 32611571 